\title{
ASSOCIATION CLINICAL-RADIOGRAPHIC OF THE ACROMION ÍNDEX AND THE LATERAL ACROMION ANGLE
}

Flavio Amado Hanciau', Marcos André Mendes da Silva², Felipe Silveira Martins ${ }^{3}$, Alexandre Ogliari ${ }^{3}$

\section{ABSTRACT}

Objective: To evaluate the clinical-radiographic subacromial disease symptoms correlated with adaptation of the measure of lateral acromion angle and its respective measuring radiographic acromial index. Methods: In the period between october 2010 and february 2011 were evaluated 55 painful shoulders with Neer test and true anteroposterior radiography. Patients were divided into two groups, with Neer test positive and negative. The index measuring the acromion and the lateral acromion angle have been standardized, and compared using statistical averages of
0.7 and $75^{\circ}$, respectively. Results: The predominant symptom in the population, females $(72.73 \%)$, age less than 59 years $(62.5 \%)$ and dominant side (65.31\%). The acromion index above 0.7 was found to be symptomatic in $66.67 \%$ and lateral acromion angle less than $75^{\circ}$ in $82.61 \%$. When associated methods, $62.5 \%$ had positive clinical $(\mathrm{p}<0.083)$. Conclusion: The determination of radiographic acromial index and the lateral acromion angle together seem to be statistically associated with the disease of subacromial impingement.

Keywords - Shoulder; Acromion/radiography; Acromioclavicular Joint

\section{INTRODUCTION}

The morphology of the acromion has been considered the main cause of subacromial disease (impingement syndrome, tendinitis and cuff rotator injuries $)^{(1-3)}$. Its differential diagnosis is of fundamental importance in the assessment of shoulder pathologies (glenohumeral instability, cervical radiculopathy, calcific tendinitis, adhesive capsulitis, isolated acromioclavicular joint pathology, osteoarthritis, and nerve compressions ${ }^{(4)}$.

Bigliani et $\mathrm{al}^{(5)}$ described the existence of three forms of acromion (flat, curved and hooked), associating the morphology found in the lateral radiographic view with the prevalence of subacromial disease (Figure 1).

The assessment of the lateral extension of the acromion causing subacromial impingement with consequent rotator cuff lesion was first reported by Nyffeler et al. ${ }^{(6)}$, who found a radiographic index that determi- ned a resulting force responsible for the subacromial impingement. This index is determined by the lines in true anteroposterior radiographic view of the shoulder, through the GA/GU relation (distance between the joint surface of the glenoid and the lateral border of the acromion, divided by the distance between the glenoid and the lateral border of the greater tubercle) (Figure 2).

The vector resulting from the force originates in the lateral projection of the acromion which, in turn, is related to the deltoid insertion, causing the humeral head to rise up and impinge against the subacromial surface during abduction of the upper limb (Figure 3) ${ }^{(6-8)}$. The greater the lateral projection of the acromion, the higher the acromial index will be, and consequently, the greater the likelihood of the occurrence of impingement syndrome ${ }^{(6)}$.

Banas et $\mathrm{al}^{(9)}$ reported the association of the angle of lateral tilt of the acromion with higher prevalence of subacromial disease. They determined, through

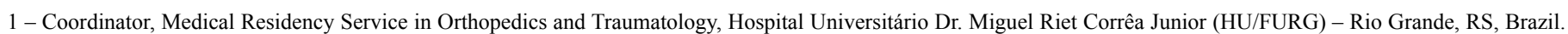

2 - Orthopedist, Shoulder Group, HU/FURG - Rio Grande, RS, Brazil.

3 - Resident Doctor, Orthopedics and Traumatology, HU/FURG - Rio Grande, RS, Brazil.

Study conducted at the Hospital Universitário Dr Miguel Riet Corrêa Junior - Trauma Center - Rio Grande, RS.

Correspondence: Rua Visconde de Paranaguá,102, Bairro Centro -96200-190 - Rio Grande, RS. Email: fhanciau@mikrus.com.br

Received for publication: 10/10/2011, accepted for publication: $2 / 3 / 2012$

The authors declare that there was no conflict of interest in conducting this work 


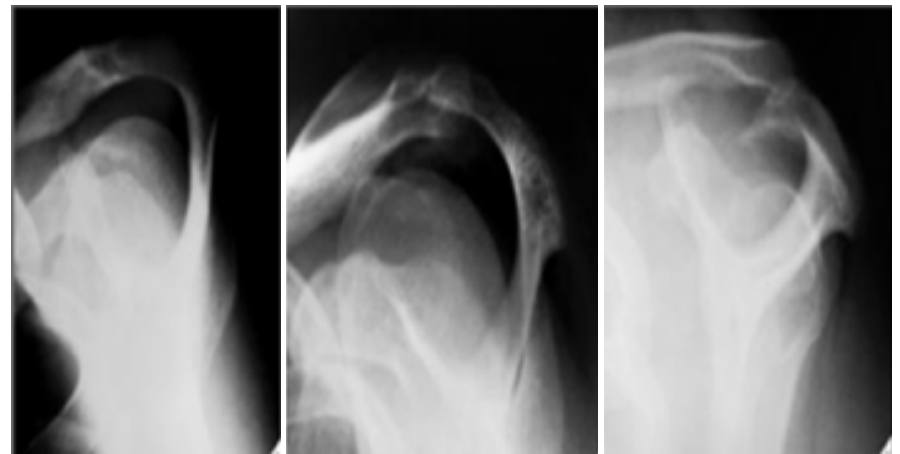

Figure 1 - Outlet (lateral) view of the acromion ${ }^{(5)}$.

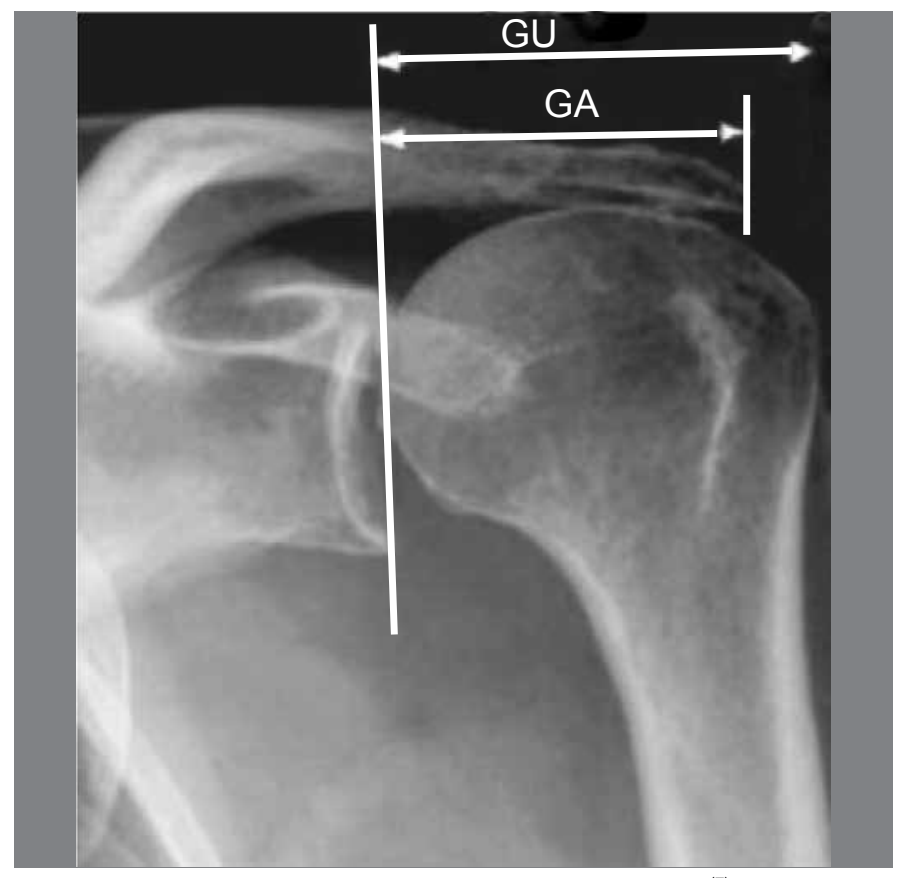

Figure 2 - Measurement of the acromial index. $A I=G A / G U^{(7)}$.

oblique coronal sections in magnetic resonance imaging (MRI), that the smaller the angle, the greater the lateral tilt of the acromion, and consequently, the greater the impingement (Figure 4).

The lateral tilt of the acromion is obtained based on lines drawn on the image, between the subacromial surface and the joint surface of the glenoid cavity ${ }^{(9)}$.

We sought to evaluate the clinical and radiological profile of patients seen in the shoulder outpatient clinic, correlating the signs and symptoms of subacromial disease (positive Neer test) with adaptation of the measurement of lateral tilt of the acromion to a radiographic measurement and its respective acromial index.

\section{MATERIALS AND METHODS}

We analyzed radiographs in true anteroposterior view of the shoulders of 88 patients treated at the

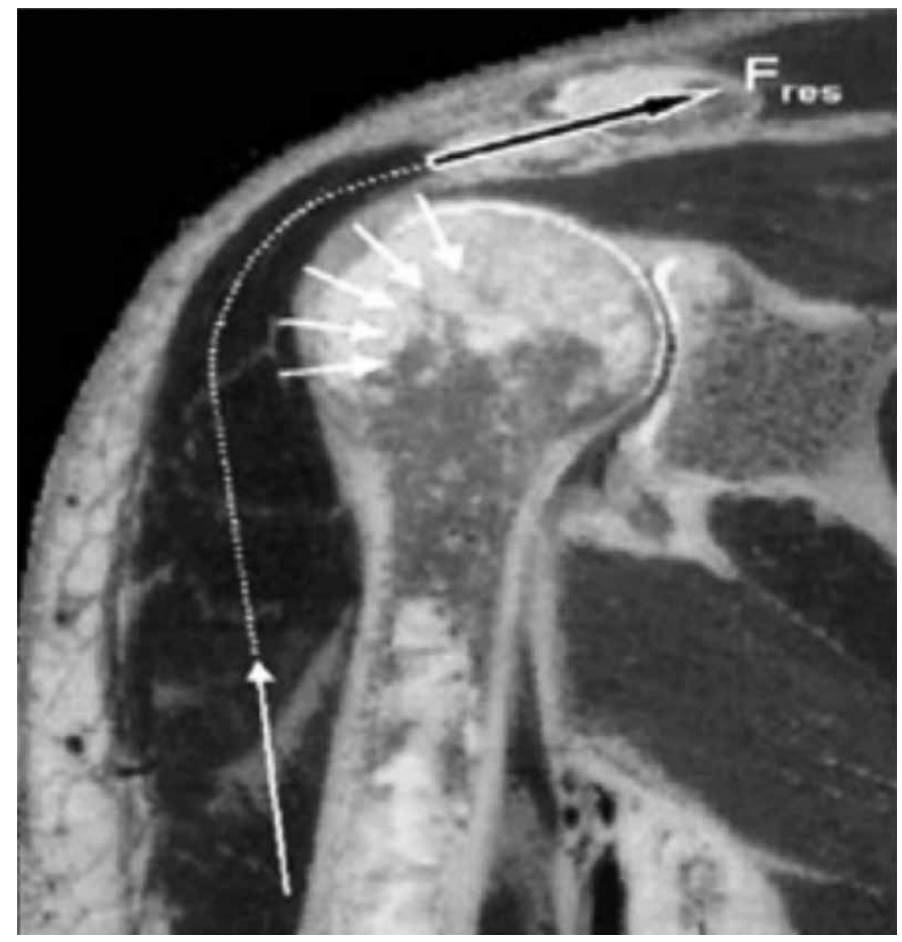

Figure 3 - Resulting force with ascension of the humeral head and probable subsequent impact. The lateral projection of the acromion will determine the acromial index ${ }^{(6-7)}$.

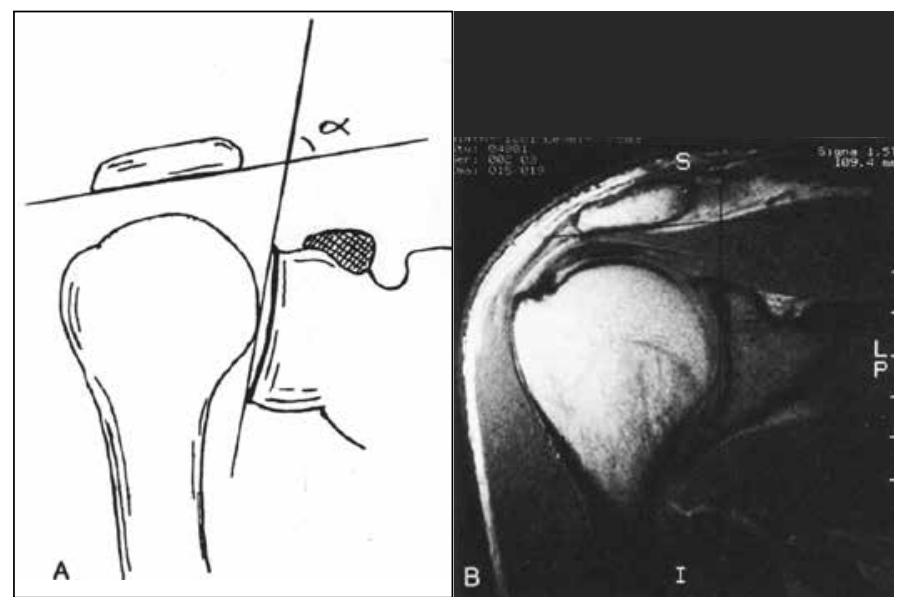

Figure 4 - Relationship between the angle of lateral tilt of the acromion and rotator cuff injury in $\mathrm{MRI}^{(9)}$.

shoulder outpatient clinic of the Hospital Universitário Dr. Miguel Riet Corrêa Junior, of the Universidade Federal do Rio Grande - RS (HU/FURG), in the period October 2010 to February 2011. The patients had shoulder pain, without previous diagnosed pathology.

Patients with a previous diagnosis of the following were excluded: osteoarthritis, uni- or multidirectional instability, cuff rotator arthropathy, adhesive capsulitis, viscous consolidations of the shoulder girdle, symptomatic acromioclavicular joint problems, cervical radiculopathy, calcific tendonitis, and nerve compression. After the exclusion, 45 patients remained, 55 
shoulders (10 patients with both shoulders affected).

The patients were assessed through a form which gathered epidemiological data on age, sex, profession, race, dominance, side of the lesion, and smoking habits. After the anamnesis, we applied the Neer test as described in the author's original article of $1983^{(10)}$.

The radiographs were standardized, with correction of anteversion of the glenoid cavity (true AP) and the proximal region of the humerus in neutral or medial rotation, all performed by the same radiology technician. Because it is an index, the focal-film distance was not considered significant ${ }^{(8)}$.

The patients were divided into two groups: symptomatic (positive Neer test), 37 (67.27\%), and non-symptomatic (negative Neer test), 18 (32.73\%).

The acromial index and the angle of lateral projection were calculated through the angular and geometric measurements, using a goniometer, determined by measurements on the radiographs, according to Nyffeler et $\mathrm{al}^{(6)}$ and Banas et $\mathrm{al}^{(9)}$, respectively.

The statistical analysis was carried out using an Excel (2007) spreadsheet, and conversion to the program Stata version 11.0. For comparison of the groups and variables, the exact Fisher's test was used. A level of significance of $5 \%$ was adopted for the two-tailed tests.

\section{RESULTS}

Females were prevalent, with $72.73 \%$ (40) of the sample, and $65 \%$ positivity in the Neer test (Figure 5 ).

Of the symptomatic patients, $62.5 \%$ were aged under 59 years (mean age 58.7 years). In patients aged over 60 years, $73.1 \%$ were symptomatic, but without statistical significance (Figure 6).

The occupation type 5 of the Brazilian Classification of Occupations (CBO) represented $68.57 \%$ of the symptomatic patients (Figure 7) ${ }^{(11)}$.

In relation to side of the lesion and dominance, we found that in $65.31 \%$ of the patients the symptoms were in the dominant limb, but without statistical significance (Figure 8).

Non-smoking individuals were more symptomatic (Figure 9).

In the assessment of the acromial index, with a relationship greater than 0.7 , we found positive symptoms in $66.67 \%$ of the shoulders, without statistical significance (Figure 10).

In the symptomatic patients, we found $82.61 \%$ of lateral tilt of the acromion with an angle of less than $75^{\circ}$, which is statistically significant (Figure 11). In the analysis of the relationship between symptoms (Neer test), acromial index greater than 0.7 , and angle of lateral tilt of the acromion $<75^{\circ}$, we detected that $82.35 \%$ of cases were correlated, once again presenting statistical significance (Figure 12).

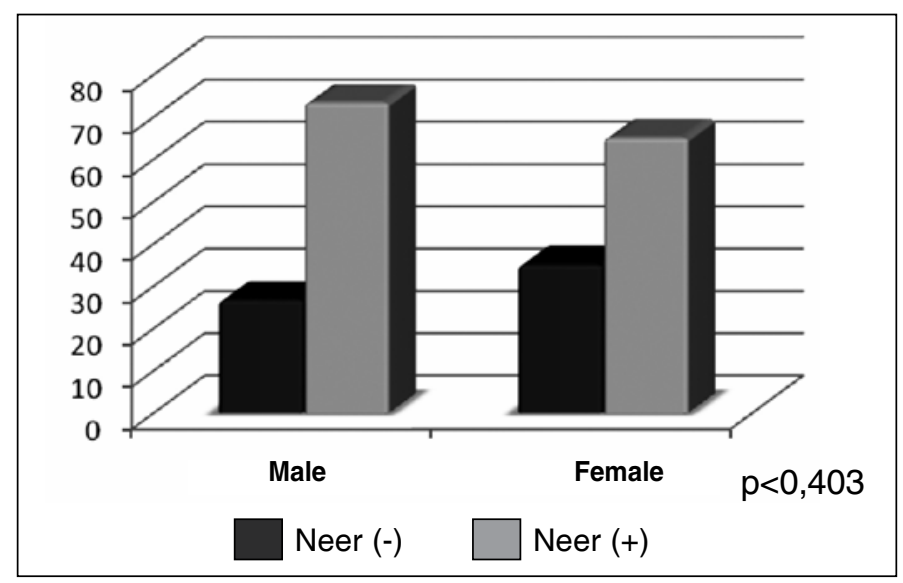

Figure 5 - Relationship between symptoms and sex.

Source: HU/FURG Archives.

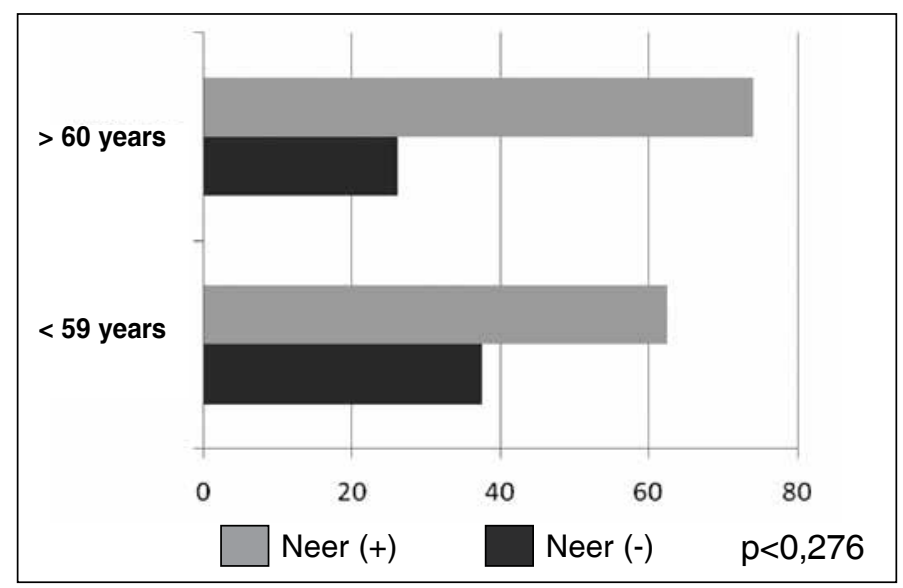

Figure 6 - Neer test and age.

Source: HU/FURG Archives.

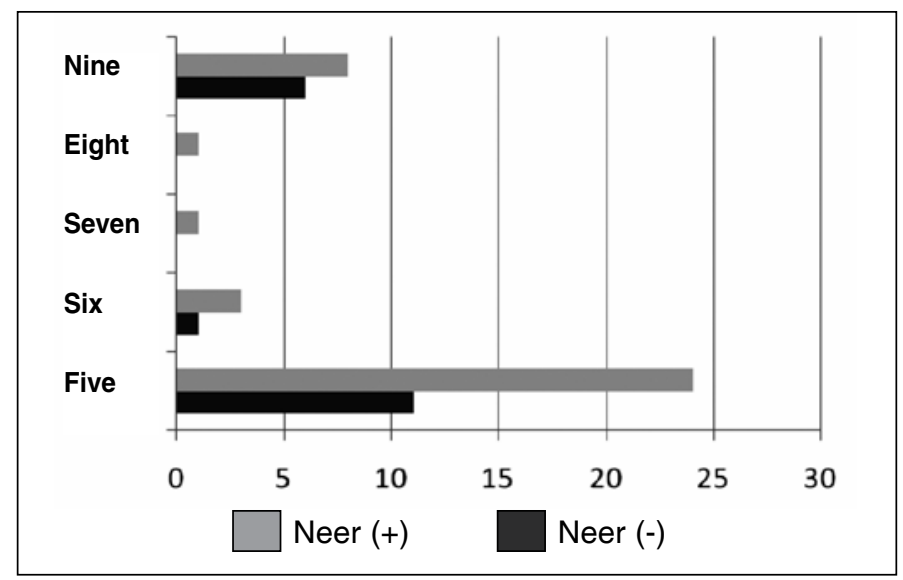

Figure 7 - Shoulder pain and occupations. Source: HU/FURG Archives. 


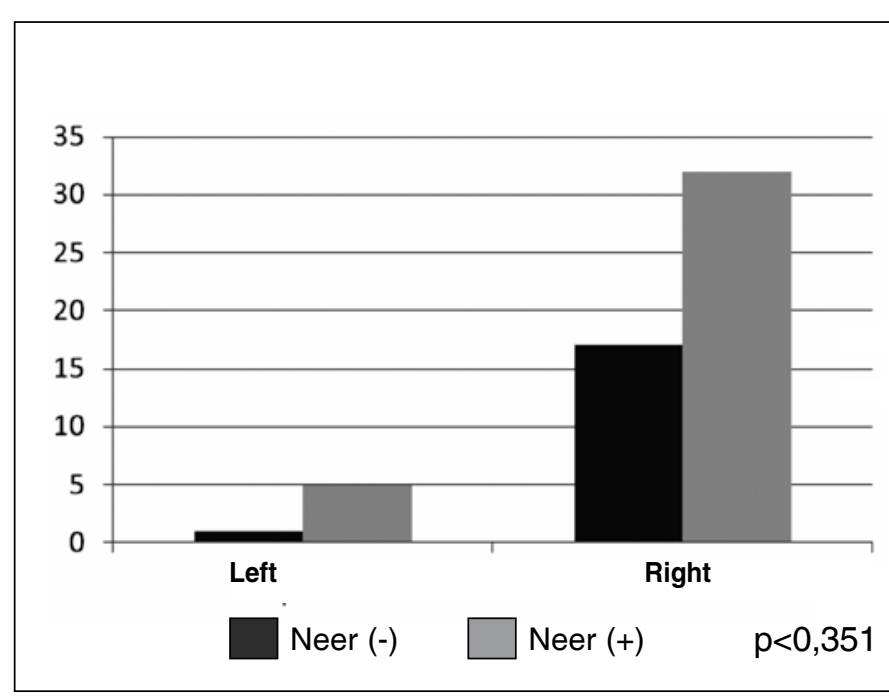

Figure 8 - Upper limb dominance and symptoms. Source: HU/FURG Archives.

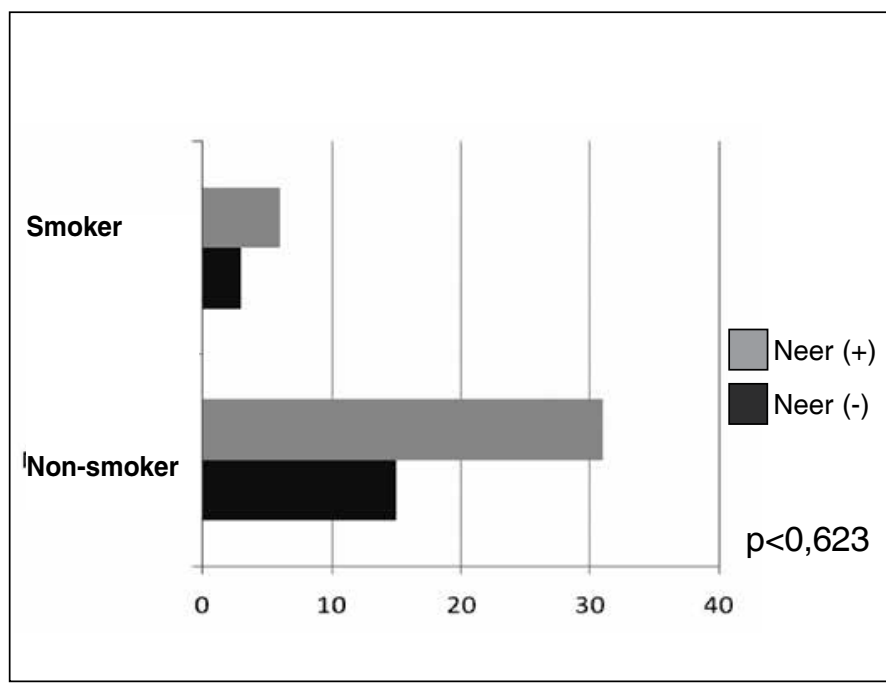

Figure 9 - Smoking and shoulder pain.

Source: HU/FURG Archives.

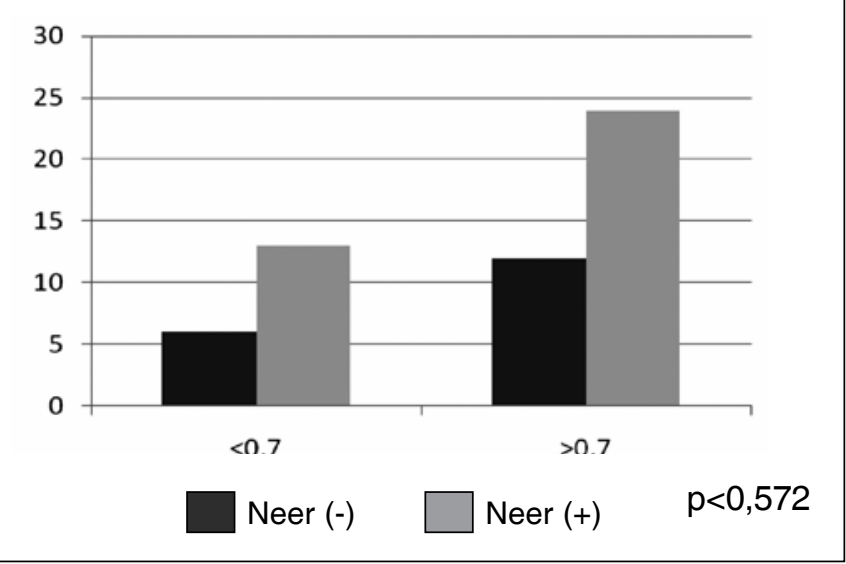

Figure 10 - Relationship between acromial index and Neer test. Source: HU/FURG Archives.

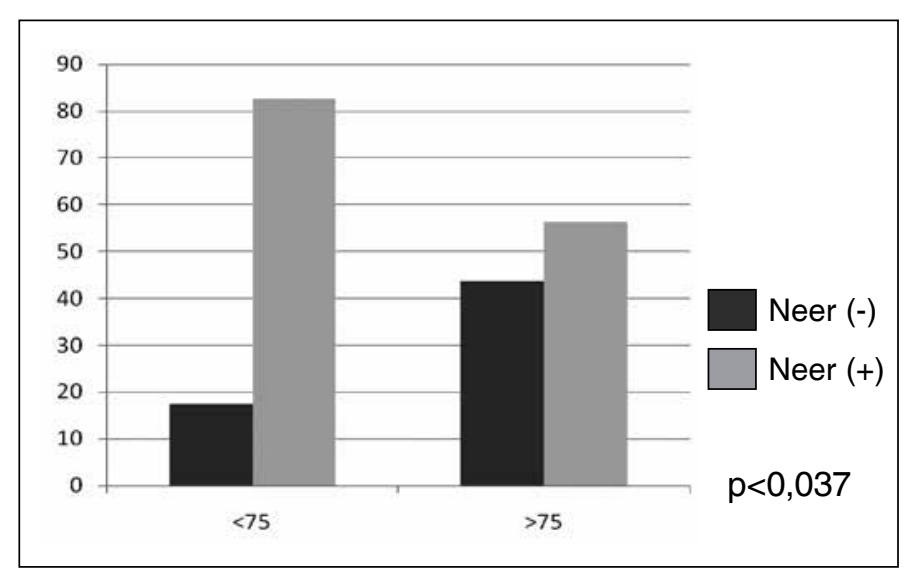

Figure 11 - Relationship between lateral tilt of the acromion and shoulder pain. Source: HU/FURG Archives.

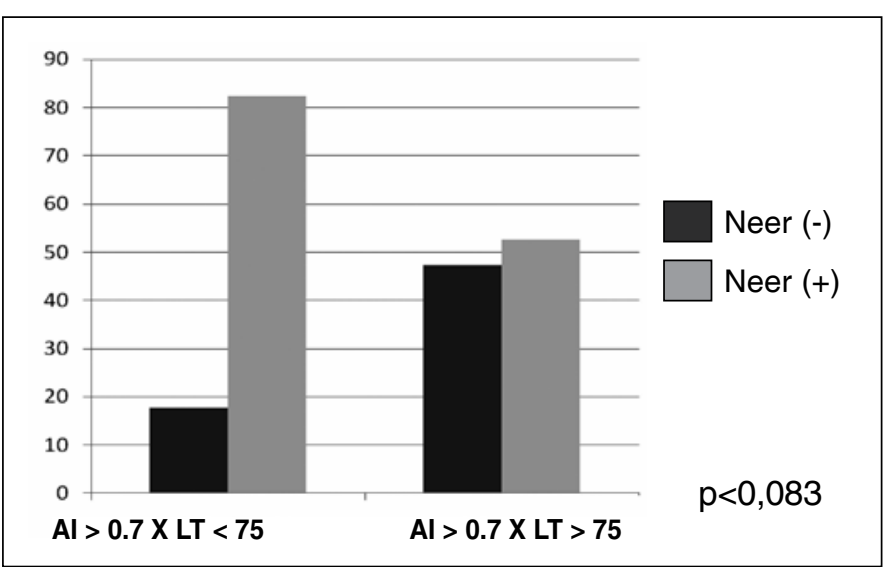

Figure 12 - Neer test, acromion index (Al) and angle of lateral tilt of the acromion (LT).

Source: HU/FURG Archives.

\section{DISCUSSION}

Studies by Bigliani et $\mathrm{al}^{(5)}$ showed that $70 \%$ of rotator cuff injuries were associated with type II acromia, and $80 \%$ were associated with hooked type acromion. We found no injury in type I acromion ${ }^{(2,5)}$.

Snyder et $\mathrm{al}^{(12)}$, in 1990 , attributed the acromial thickness, in its anterior third, to an etiological role in the subacromial disease.

The pathogenesis of the rotator cuff injury in the impingement syndrome has been a source of controversy. The theory that the structures of the "coracoacromial arch" impact against the tendons of the rotator cuff is the main factor responsible for the rupture, while biological aging, or poor local vascularization of the tendon in its insertion, is the intrinsic tendinous factor, resulting in weakness of the rotator cuff, causing the humeral head to rise up with impact and the formation of subacromial ossification ${ }^{(13,14)}$. The initial involvement of the supraspinatus tendon 
is almost invariably part of the hypovascular physiopathology, arising from a zone of approximately one centimeter in diameter, defined as the critical zone of Codman and Akerson ${ }^{(15)}$, and which Rathbun and Macnab $^{(16)}$ determined worsening of the vascular deficit when the tendon is under tension, i.e. in adduction.

The theory of hypovascularization was reinforced by Godinho et al ${ }^{(17)}$ who found $80 \%$ little or no vascularization in arthroscopic biopsies of patients with supraspinatus tear.

Jacobson et $\mathrm{al}^{(18)}$ showed that there are high levels of inter- and intraobserver variation when differentiating between the three types of acromion. They conclude that determining the form of the acromion based on the Bigliani system is not reliable.

The discrepancy as to the type of acromion in observations between radiologists and orthopedists was reported by Toivonen et $\mathrm{al}^{(19)}$, who suggested calculating the acromial angle in oblique sagittal images of magnetic resonance imaging, correlating with the classification of Bigliani. Thus, they defined better intraobserver applicability.

Based on these observations, Nyffeler et $\mathrm{al}^{(6)}$ and Banas et $\mathrm{al}^{\left({ }^{(9)}\right.}$ published the angle of lateral tilt and the acromial index, according to MRI and radiographic assessments, respectively. Based on this, they defined a statistically significant relationship whereby the smaller the angle of lateral tilt, and the greater the acromial index, the greater the symptoms and prevalence of subacromial pathology $\mathrm{y}^{(4,6,9)}$.

By means of simple radiographic analysis, our study calculated the angle of lateral tilt and the acromial index, evaluating the epidemiological data and correlating the presence of pain (positive Neer test).

We adapted the evaluation of the lateral projection of the acromion for radiography, due to the greater availability of this exam in the Brazilian National Health System (Sistema Único de Saúde, SUS), and to determine whether there is a clinical-radiographic correlation.

The magnetic resonance image is definitely more accurate for measuring the acromial geometries, such as their form and lateral extension, as well as calculating the angle of lateral tilt, which may be associated with rotator cuff disorders, and documenting the presence or absence of injury of this structure ${ }^{(20)}$.

According to Serna and Velásquez ${ }^{(7)}$, the assessment of the acromial index by MRI presents highly statistically significant values, with greater reliability than when evaluated radiologically. However, highly significant results were also found in the radiographic assessment $^{(8)}$.

Our findings were without statistical significance in relation to age, sex, profession, race, smoking, occupation, dominance, and side of the lesion. The final assessment suggested that because the population sampled was relatively small, the data did not show statistical significance. However, there was a prevalence of females (over 70\%), and this group presented higher positive symptoms in relation to men, according to previous works ${ }^{(6,9)}$.

In the isolated evaluation of the acromial index, we detected the presence of a positive clinical association, with levels suggestive of subacromial pathology, i.e. higher than 0.7 in $66.67 \%$ of the population sampled. We used this cut-off point, as shown in the works of Nyffeler et al. ${ }^{(6)}$ and Miyazaki and Fregoneze ${ }^{(8)}$, in which the values found were $0.73 \pm 0.06$ and 0.7194 , respectively. However, our findings were not statistically significant $(\mathrm{p}<0.572)$.

The lateral tilt of the acromion presented a closer clinical correlation $(82.61 \%)$ when evaluated in isolation, and compared with the acromial index. We found statistical significance in this aspect $(p<0.037)$.

Evaluating the lateral tilt and the acromial index together, with the positive Neer test, we found statistically significant data $(\mathrm{p}<0.083)$, increasing the reliability of the assessment of the radiographic angle of lateral tilt.

\section{CONCLUSION}

Isolated assessment of the lateral tilt of the acromion with symptomatic patients (positive Neer test) demonstrated higher statistical significance than the acromial index $(p<0.047)$. An acromial index $>0.7$ was only clinical important when associated with the lateral tilt of the acromion $<75^{\circ}(\mathrm{p}<0.083)$.

Further studies are necessary, with larger case series, correlating the measurement of the methods described here with the diagnosis confirmed by gold standard methods (magnetic resonance imaging and videoarthroscopy) before we can consider these parameters reliable in screening to determine which patients will develop subacromial disease. 


\section{REFERENCES}

1. Lee SB, Itoi E, O'Driscoll SW, An KN. Contact geometry at the undersurface of the acromion with and without a rotator cuff tear. Arthroscopy. 2001;17(4):365-72.

2. Neer CS 2nd. Anterior acromioplasty for the chronic impingement syndrome in the shoulder: a preliminary report. J Bone Joint Surg Am. 1972;54(1):41-50.

3. Chambler AF, Emery RJ. Acromial morphology: the enigma of terminology. Knee Surg Sports Traumatol Arthrosc. 1997;5(4):268-72.

4. Bigliani LU, Levine WN. Subacromial impingement syndrome. J Bone Joint Surg Am. 1997;79(12):1854-68.

5. Bigliani LU, Morrison DS, April EW. The morphology of the acromion and its relationship to rotator cuff tears. Orthop Trans. 1986;10:228.

6. Nyffeler RW, Werner CM, Sukthankar A, Schmid MR, Gerber C. Association of a large lateral extension of the acromion with rotator cuff tears. J Bone Joint Surg Am. 2006;88(4):800-5.

7. Serna JL, Velásquez JM. Efecto del índice acromial en la ruptura del manguito rotador. Rev Colomb Ortop Traumatol. 2007;21(2):112-8.

8. Miyazaki NA, Fregoneze M. Estudo radiográfico do índice acromial e sua relação com as lesões do manguito rotador. Rev Bras Ortop. 2010;45(2):151-4.

9. Banas MP, Miller RJ, Totterman S. Relationship between the lateral acromion angle and rotator cuff disease. J Shoulder Elbow Surg. 1995;4(6):454-61.

10. Neer CS 2nd. Impingement lesions. Clin Orthop Relat Res. 1983;(173):70-7.

11. Ministério do Trabalho e Emprego. Disponível em: <http://www.mtecbo.gov.br/ cbosite/pages/informacoesGerais.jsf>. Acesso em: 20 março, 2011.
12. Snyder SJ, Karzel RP, Del Pizzo W, Ferkel RD, Friedman MJ. SLAP lesions of the shoulder. Arthroscopy. 1990;6(4):274-9.

13. Ozaki J, Fujimoto S, Nakagawa Y, Masuhara K, Tamai S. Tears of the rotator cuff of the shoulder associated with pathological changes in the acromion. A study in cadavera. J Bone Joint Surg Am. 1988;70(8):1224-30.

14. Flatow EL, Soslowsky LJ, Ticker JB, Pawluk RJ, Hepler M, Ark J, et al. Excursion of the rotator cuff under the acromion. Patterns of subacromial contact. Am J Sports Med. 1994;22(6):779-88.

15. Codman EA, Akerson IB. The pathology associated with rupture of the supraspinatus tendon. Ann Surg. 1931;93(1):348-59.

16. Rathbun JB, Macnab I. The microvascular pattern of the rotator cuff. J Bone Joint Surg Br. 1970;52(3):540-53.

17. Godinho GG, Freitas JMA, França FO, Filho JSA, Schio C, Júnior SCP. Estudo da vascularização das bordas das lesões nas roturas completas do manguito rotador. Rev Bras Ortop. 2007;42(6):169-72.

18. Jacobson SR, Speer KP, Moor JT, Janda DH, Saddemi SR, MacDonald PB, et al. Reliability of radiographic assessment of acromial morphology. J Shoulder Elbow Surg. 1995;4(6):449-53

19. Toivonen DA, Tuite MJ, Orwin JF. Acromial structure and tears of the rotator cuff. J Shoulder Elbow Surg. 1995;4(5):376-83.

20. Jost $B$, Gerber $C$. What the shoulder surgeon would like to know from MR imaging. Magn Reson Imaging Clin N Am. 2004;12(1):161-8. 